Historic, Archive Document

Do not assume content reflects current scientific knowledge, policies, or practices. 



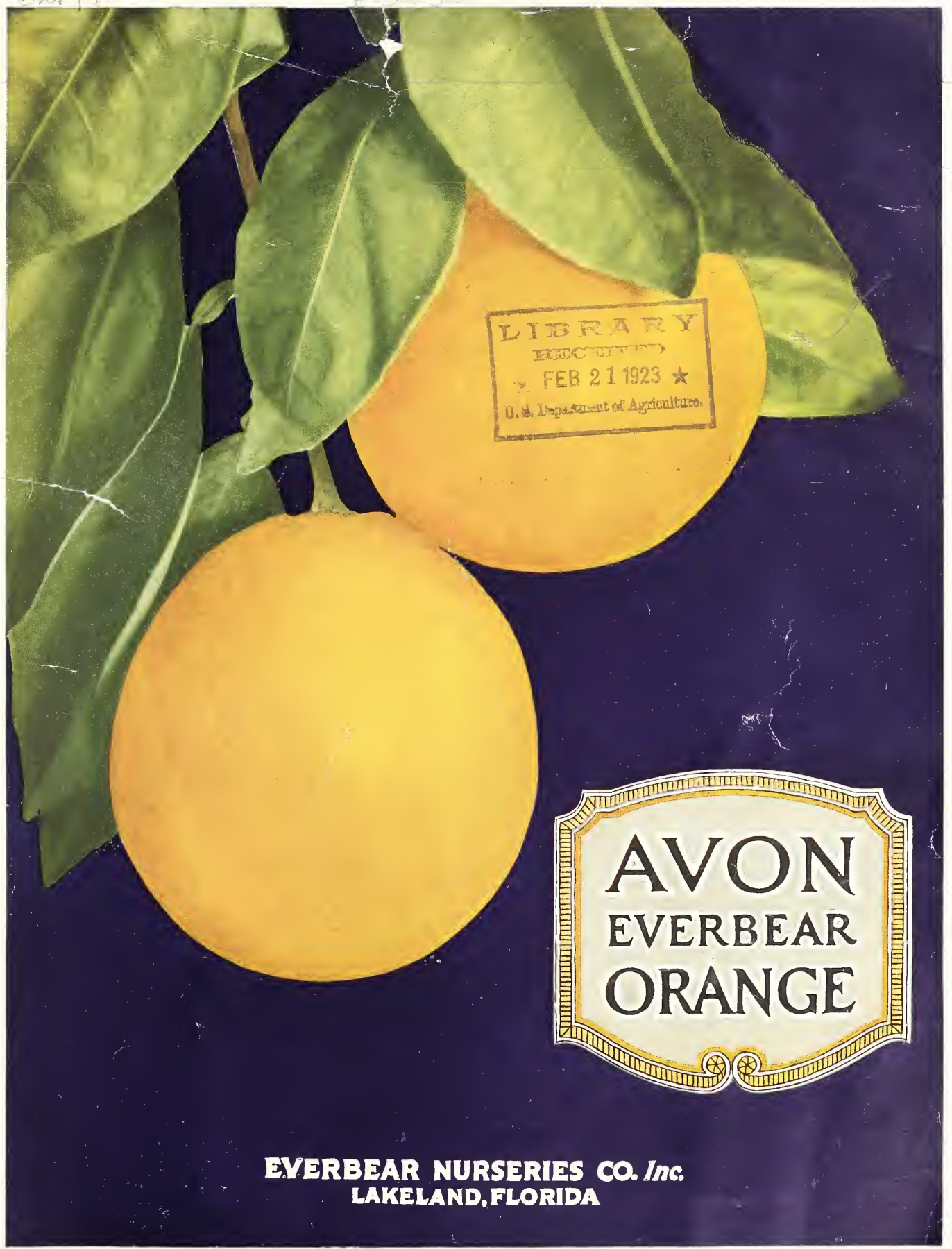




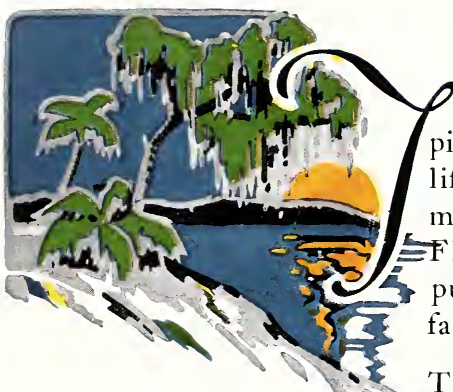

\section{The Avon Everbear Orange}

HE marvelous Orange Tree from which can be picked seventy-five per cent of its fully-matured, prolific crop, optionally in June or July-completely monopolizing the demand of a market hungry for ing a late bearing charadteristic exclusively its own; it is the only orange tree in all the realms of Florida citrus culture that bears heavy crops of popular size oranges of wondrous, luscious flavor, at a season when all other types of oranges are off the market.

Who can even estimate the augmented flow of golden profits that will pour into the pockets of progressive orange growers when this astonishing tree has become extensively planted and trains of freight cars are rushing Avon Everbear Oranges to a waiting, depleted northern market - a market eager to buy Florida oranges. The profit returns will usher in a new day for Florida; a day of wider net margins of gain and a new high level of achievement in Florida citrus development.

\section{Nine Years, Sworn-to Performance GUARANTEES FIXED BEARING HABITS}

The two marvelous parent trees-the trees that will be honored in Florida history as the noble ancestors of thousands of Everbear Orange Trees in the years to come, had been in continuous blooming and fruit-setting for nine years before they attracted the serious attention of pomologists.

At the end of August, I 922, these parent trees were observed to be heavy with fruit despite there having been a number of boxes of oranges picked from each tree for sampling purposes.

And while the Avon Everbear Orange will be at top market quality for shipment during June and July, the fruit full juiced, deliciously showed only a slight ers who have investiga yield for I 922 to run

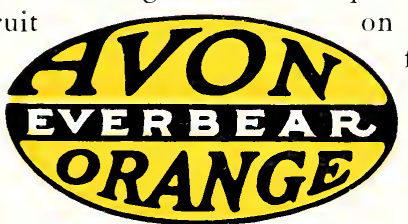
on the above date was practically flavored, wholly enjoyable and drying of the skin. The growted these trees estimate their twelve to fifteen boxes per tree. 


\section{The World's gCost Amazing Citrus Tree}

The Avon Everbear Orange is of the true Valencia type. Thin skin, fine texture, very juicy, an aroma and flavor more readily announced by taste than described by words, good color, few seeds and little rag. Size may be expected to average from I 76 's to I 50's, although a substantial percentage of each crop will run larger while some of the fruit may run as small as 200's.

Avon Everbear Orange Trees will follow a heavy-yield habit and may be expected to produce prolifically during May, June and July each year, occupying a marker free from the competition of any other Florida varieties.

The qualities that are most continuously searched for by discriminating purchasers of oranges, are so abundantly and conspicuously embodied in the Avon Everbear Orange that it will easily outdistance all other varieties in popularity and sales volume, assuring both producer and seller a most remarkable profit because it will fill a sales gap never before filled by any other variety of Florida oranges.

But when all other varieties have had their brief sales day, and the last of the last box are withering on the grocers' and fruiterers' stands, behold the triumph of the Avon Everbear; coming in gorgeous, juicy perfection, into an empty, clamorous market; picture its welcome, picture the surprise and the revel of delight of orange lovers, picture the lively sales, the unprecedented prices, and the producer's magnificent profits.

The type and character of the men who direct the operations and policy of Everbear Nurseries Company, Inc., is a positive assurance of the faithful execution of every contract and every uridertaking into which the company enters.

From the many congratulatory expressions we have received in connection with this orange tree of golden promise we reprint one from a man whose word is valuable indeed. Mr. A. M. Tilden, a large citrus grower of Winterhaven, Florida, said: "This tree is a God-send to the people contemplating planting orange trees as they can plant a variety that will spread the bulk of their crop over a period in which there are no shipments at present."

The two outstanding and predominating characteristics of this orange are: first, it will positively set a full crop of fruit each year, because it will continue to bloom until it has set a full crop; second, $75 \%$ of the crop matures 60 days after the latest known other variety has matured.

Now Booking Orders for I922-23 Delivery

EVERBEAR NURSERIES COMPANY, Inc r! Lakeland, Florida

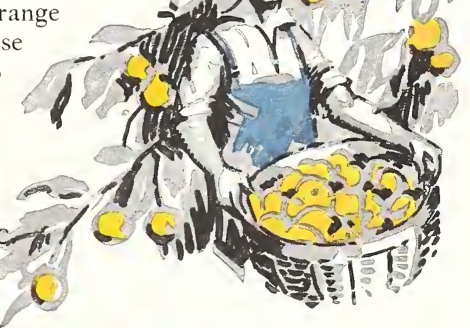




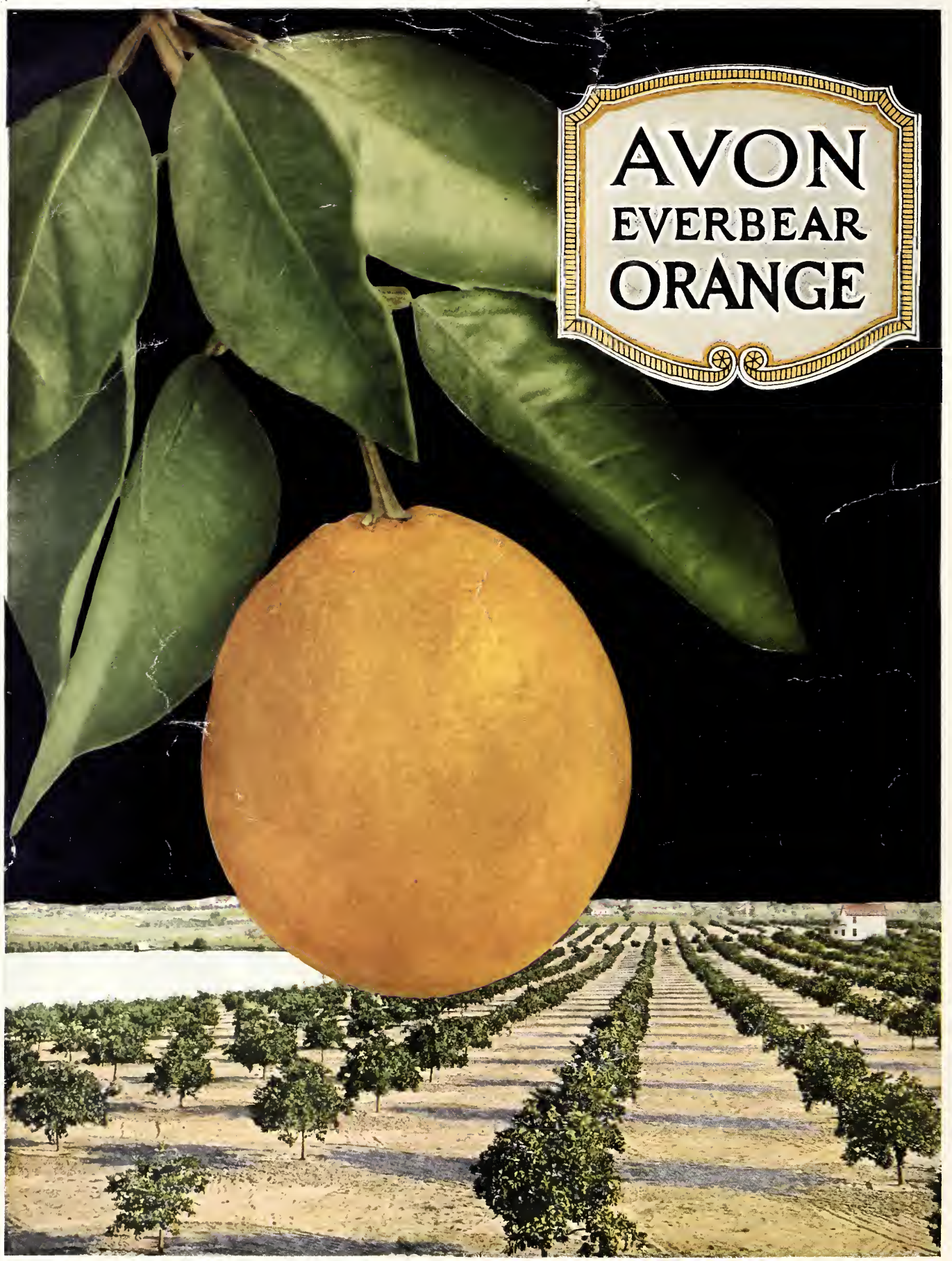

